\title{
Biological basis for the clinical use of interferon
}

\author{
F Dianzani
}

\begin{abstract}
Interferons are proteins produced by certain cells in response to stimuli such as foreign cells (including tumour cells), bacteria, and viral antigens. They interact both with the interferon producing cells and other cells through production of effector proteins. There are three main types of interferons, known as $\alpha, \beta$, and $\gamma$, which have direct antiviral and immunomodulatory effects. Antiviral effects may include inhibition of viral replication, protein synthesis, maturation, or release from infected cells. Immunomodulating effects may include enhancement of macrophage, cytotoxic $T$ cell, and natural killer cell activity. In chronic viral hepatitis, the precise mechanisms of action of $\alpha$ interferon are not yet certain. Patients with chronic hepatitis B, however, have been shown to lack endogenous interferon production; those who respond to $\alpha$ interferon treatment show a characteristic peak in serum aminotransferase activity before resolution of the infection, indicating an immune reaction. In chronic hepatitis $C$, the antiviral effect may be more important; patients who respond to $\alpha$ interferon tend to have higher values of $2^{\prime} 5^{\prime}$ oligo adenylate synthetase, an enzyme induced by interferons that breaks down viral RNA. The clinical relevance of antiinterferon neutralising antibodies produced by some patients during interferon treatment has yet to be firmly established.
\end{abstract}

(Gut 1993; supplement: S74-S76)

Interferons are proteins produced by certain cells in response to various stimuli, including foreign nucleic acids, foreign cells (including tumour cells), bacteria, and viral antigens. In particular, they represent the body's first line of defence against viral infection. Once interferon is released by the cell, it interacts with specific receptors, either on the same cell or on other cells, by inducing effector proteins. Only when these effector proteins have been produced may the cell become resistant to viral infection. The effect of interferon is increased by the transfer of these proteins to cells that have not experienced interferon inducers or interferon. ${ }^{1}$

There are at least 20 genes coding for three main types of interferon $(\alpha, \beta$, and $\gamma)$, and at least another 23 genes coding for the effector proteins. $\beta$ Interferon, produced mainly by fibroblasts and epithelial cells, was the first to be discovered ${ }^{2}$ and is also the first to appear in response to viral infection. $\alpha$ Interferon is produced by B lymphocytes, null lymphocytes, and macrophages, ${ }^{3}$ and differs both antigenically and structurally from $\beta$ interferon. $\gamma$ Interferon differs molecularly and antigenically from both the other interferons and is produced by $\mathrm{T}$ lymphocytes sensitised to foreign antigens.

\section{Antiviral effects}

The mechanism by which interferons affect viral replication is very complex. The proteins produced include 2 ' 5 ' oligo adenylate synthetase, $\mathrm{Mx}$ proteins, and dsRNA dependent protein kinase. The mechanisms of action of these remain uncertain. It is clear, however, that viral replication can be interrupted at any stage in the replicative cycle. Production of $2{ }^{\prime} 5^{\prime}$ oligo adenylate synthetase has been shown to lead to breakdown of viral single stranded $\mathrm{RNA},{ }^{4}{ }^{5}$ while $\mathrm{Mx}$ proteins (produced only by $\alpha$ and $\beta$ interferon) inhibit production of influenza virus mRNA in the nucleus of the infected cell. ${ }^{6}$ In tissue cultures infected with vesicular stomatitis virus, just 10 units of $\alpha$ or $\beta$ interferon have been shown to have a marked inhibitory effect on viral growth. ${ }^{7}$ Increasing the dose of interferon up to 100 units resulted in further inhibition until a plateau phase was reached with no further modification of growth at higher doses.

Other antiviral activities may include prevention of the start and continuation of viral protein synthesis, maturation of viral proteins, and release of virions from the infected cell.

\section{Cell mediated effects}

Interferons also act on cell functions, including cell differentiation and modulation of the immune system. In this way, interferon may inhibit cell replication but enhance the functions of fully differentiated cells, including an increase in antibody production and macrophage and cytotoxic cell activity. For example, macrophages cultivated in the presence of Candida albicans show greatly enhanced phagocytic activity when interferon is added. ${ }^{8}$ In another study of cultures infected with HIV, there was little inhibition of viral growth with interferon alone (even at high doses) but the addition of peripheral blood mononuclear leucocytes from a healthy donor enhanced strongly the antiviral effect. ${ }^{9}$ Interferon in this way has an indirect effect by enhancing cytotoxic $T$ cell activity. Similarly, natural killer cell activity has been shown to be increased by interferons, ${ }^{10}$ particularly $\gamma$ interferon. ${ }^{11}$

Interferons are also able to modulate the expression of other cytokine receptors on cells, including interleukin 2 and tumour necrosis 
factor $\alpha,{ }^{12}$ and can increase expression of the Fc receptor on macrophages. ${ }^{13}$ If these immunomodulatory effects of interferon are to succeed, a fully reactive immune system is imperative. The lack of efficacy seen in immunosuppressed patients is evidence of this.

\section{Dose response relation}

The amount of interferon given is also important. Data from Norway have shown that certain doses of interferon enhanced both phagocytic and natural killer cell activity, while higher doses decreased this activity. ${ }^{14}$ Thus, there may be an optimal dose of interferon which may vary from one patient to another. In studies of patients with renal cell carcinoma treated with doses of $\alpha$ interferon from 3 to 150 million units (MU), the complete response rate overall was less than $2 \%$ and the complete plus partial response rate less than $20 \%{ }^{15}$ Patients treated with more than $20 \mathrm{MU}$, however, were found to have a response rate of about $13 \%$, while twice as many responded to treatment with 10 to $20 \mathrm{MU}$. Even those treated with less than $10 \mathrm{MU}$ had a significantly better response rate compared with the patients on a high dose. Thus, for immune modulation, a high dose of interferon may not be necessary or even helpful.

\section{Interferon in viral hepatitis}

Of the three interferons, $\alpha$ interferon has shown the most benefit in patients with chronic viral hepatitis. In chronic hepatitis B patients who respond to treatment with $\alpha$ interferon, there is an immediate reduction in viral DNA and usually serum aminotransferase activities, followed by a sudden peak in aminotransferase activity about two to three months after the treatment is started. This suggests that the initial response is because of interferon's direct antiviral activity while the second phase is mediated by an immune mechanism. This effect may be because it has been found that interferons enhance expression of both class I and II HLA antigens in virus infected cells. ${ }^{16} 17$ In vitro studies have shown that $\alpha$ interferon enhances HLA 1 antigen expression, which in turn allows viral antigens to be presented on the cell surface, resulting in recognition and lysis by cytotoxic cells. ${ }^{18}$ HLA 2 antigen expression may also be increased, which may result in stimulation of CD4+ lymphocytes and ultimately antibody production by $\mathrm{B}$ cells, ${ }^{18}$ but further studies are needed to confirm the relation of these. Interferon's enhancement of cytotoxic $\mathrm{T}$ cell and natural killer cell activity described above also plays an important part in defeating hepatitis B infection.

Studies in patients with chronic hepatitis B have shown that at least some of them have a defect in their endogenous interferon production, ${ }^{19} 20$ providing a rationale for interferon treatment in this disease. In particular, leucocytes from children with chronic hepatitis B do not produce interferon in response to viral stimulation while control cells show a good interferon response. ${ }^{19}$
The liver damage seen in chronic hepatitis $\mathrm{C}$ infection seems to be caused by a direct cytopathic effect of the virus itself rather than by an immune response, as in hepatitis B. Thus the antiviral activity of interferon may be more important than its immunomodulating effects in this setting. Moreover, as the hepatitis C virus seems to be very sensitive to $\alpha$ interferon, a higher rate of responders to lower interferon doses is often seen. Since the interferon induced antiviral state decays with time after removal of interferon, however, relapses are often seen in the patients responding to treatment when the treatment is stopped. Usually the response is established again by interferon being reintroduced.

\section{Variables affecting response to interferon}

The specific type of viral infection may influence the role of, and response to, interferon. Viruses that kill the cell before being released usually cause very acute infections and are not good targets for interferon. Viruses that mature on the cell surface, however, need to keep the cell alive for as long as possible; in this case, interferon can have both a direct effect on viral growth and an indirect effect mediated by viral antigen expression on the cell membrane. In other infections, the virus does not replicate independently and the viral genome becomes integrated into that of the host cell (as in long standing hepatitis B infections). Here, the only possible effect is that mediated by viral antigen expression - that is, an immune response rather than a direct antiviral effect. Studies have shown, however, that interferon does not inhibit expression of viral sequences once integrated into cellular DNA. ${ }^{21} 22$

The pharmacokinetics of interferon inevitably affect its activity. For example, treatment with $\alpha$ interferon results in high concentrations in the liver and kidneys but poor distribution to solid tumours. ${ }^{23}$ Therefore, a reduction in tumour burden must be achieved to allow interferon to reach the transformed cells.

Interferon induced resistance to viral infection in a cell continues for a time even when the interferon is stopped. The effect lasts longer following prolonged treatment with interferon than it does following a pulse of interferon. ${ }^{24}$ With high doses of interferon, however, the end result may be down regulation of the interferon receptor leading to the lack of response to interferon seen in previous studies. This implies that the continuous presence of interferon in the circulation is not only useless but it may even be detrimental.

\section{Predictors of response during $\alpha$ \\ interferon treatment}

Patients with chronic hepatitis B who respond well to $\alpha$ interferon treatment show the typical clinical course described above, with a characteristic peak in serum aminotransferases just before resolution of the infection. Those who do not show this peak are less likely to have a complete response, even if some modulation of 
TABLE I Incidence of antibodies in patients treated with recombinant interferon ( $r$ IFN alfa-2a or rIFN alfa-2b) or lymphoblastoid interferon (IFN alfa-N1) (from Antonelli et al) ${ }^{25}$

\begin{tabular}{ll}
\hline Treatment & Neutralising antibody positive/tested (\%) \\
\hline rIFN alfa-2a & $15 / 74(20 \cdot 2)$ \\
rIFN alfa-2b & $10 / 144(6 \cdot 9)^{\star}$ \\
rIFN alfa-N1 & $1 / 78(1 \cdot 2)^{\star \star}$ \\
\hline${ }^{\star} \mathrm{p}<0 \cdot 01$. &
\end{tabular}

TABLE II Effect of antibody to interferon alfa-2a in patients with chronic hepatitis $C$ (from Dianzani et al) ${ }^{26}$

\begin{tabular}{|c|c|c|c|}
\hline \multirow[t]{2}{*}{ Number of patients } & & \multicolumn{2}{|c|}{ Anti-IFN neutralising antibody assay } \\
\hline & & $\overline{\text { Negative (\%) }}$ & Positive (\%) \\
\hline $\begin{array}{l}\text { Responders } \\
\text { Non-responders }\end{array}$ & $\begin{array}{l}30(63 \cdot 8) \\
17(36 \cdot 2)\end{array}$ & $\begin{array}{r}26(81 \cdot 3) \\
6(18 \cdot 7)\end{array}$ & $\begin{array}{c}4(26 \cdot 6) \\
11(73 \cdot 4)^{\star}\end{array}$ \\
\hline
\end{tabular}

${ }^{\star} \mathrm{p}<0.0004$ compared with responders.

aminotransferases has been seen. Studies have also shown that patients with chronic hepatitis $\mathrm{C}$ who respond to treatment with $\alpha$ interferon have a higher percentage increase in $2^{\prime} 5^{\prime}$ oligo adenylate synthetase production than those who do not respond, and that this increase persists during a six month period of study.

Induction of anti-interferon neutralising antibodies may also influence response. One study showed that recombinant interferon alfa-2a (ROFERON, Roche, Basle) induced neutralising antibodies in about $20 \%$ of patients with chronic viral hepatitis. ${ }^{25}$ Only about $6 \%$ of those treated with recombinant interferon alfa-2b (INTRON A, ScheringPlough, Kenilworth) produced antibodies and even fewer of those given natural $\alpha$ interferon (Table I). Furthermore, the titre of neutralising antibodies was much higher in those receiving alfa-2a compared with those on alfa- $2 b$ or natural interferon.

The clinical relevance of these antibodies has yet to be firmly established. In a study of patients with chronic hepatitis $\mathrm{C}$ treated with interferon alfa-2a, 30 responded with normalisation of serum aminotransferase activity. ${ }^{26}$ Among these responders, 26 were negative for neutralising antibodies and only four were positive. Among those who did not respond, this ratio was reversed, suggesting that neutralising antibody formation may be a factor for non-response to interferon alfa-2a (Table II). The clinical course is apparently unaffected in some patients, however, who do develop antibodies to interferon alfa-2a. In some of these patients, it may be that the disease was already cured by the time the antibodies were produced.

\section{Conclusions}

Interferons have a wide range of effects, including direct anti-viral and anti-tumour responses as well as modulation and enhancement of the cell mediated immune system. In chronic viral hepatitis, $\alpha$ interferon treatment has beneficial effects although the precise mechanisms of action are not yet certain. There are indications, however, suggesting that in chronic hepatitis $\mathbf{B} \alpha$ interferon may act as both an antiviral and immunomodulatory agent, while in chronic hepatitis $C$ the main action seems to be antiviral.

1 Blalock JE, Stanton GJ, Weigent DA. Cell-to-cell transmission of IFN-induced activities. In: Baron $S$ Dianzani F, Stanton GJ, Fleischmann WR Jr, eds. The interferon system: a current review to 1987. Austin: interferon system: a current review to 1987. Austin: Science, 1987: 234-40.

2 Isaac A, Lindenmann J. Virus interference: I. The interferon. Proc $R$ Soc Lond (Biol) 1957; 147: 258-73.

3 Dianzani F, Capobianchi MR. Mechanism of induction of alpha interferon. In: Baron S, Dianzani F, Stanton GJ, Fleischmann WR Jr, eds. The interferon system: a curren review to 1987. Austin: University of Texas Medica Branch Series in Biomedical Science, 1987: 21-30.

4 Lengyel P. Biochemistry of interferons and their actions. Annu Rev Biochem 1982; 51: 251-8.

5 Samuel CE. Interferon induction of the antiviral state: Proteins induced by interferons and their possible roles in Proteins induced by interferons and their possible roles in the antiviral mechanisms of interferon action. In: Pfeffer LM, ed. Mechanisms of interferon

6 Horisberger MA, Staeheli P, Haller O. Interferon induces a unique protein in mouse cells bearing a gene for resistance to influenza virus. Proc Natl Acad Sci USA 1983; 80: 1910-4

7 Oleszak E, Stewart EW II. Potentiation of the antiviral and anticellular activities of interferons by mixtures of HuIFN- $\gamma$ or HuIFN- $\beta$. $\mathcal{f}$ Interferon Res 1985; 5: 361-71.

8 De Maeyer E, De Maeyer-Guignard J. Enhanced phagocytic activity of macrophages against Candida albicans. Interferon immunity. In: Baron S, Dianzani F, Stantonor immunity. In: WR Jr, The review to 1987. Austin: University of Texas Medical review to 1987. Austin: University of Texas Medic

9 Dolei A, Fattorossi A, D'Amelio R, Aiuti F, Dianzani F. Direct and cell-mediated effects of interferon- $\alpha$ and $-\gamma$ on cells chronically infected with HTLV-III. $\mathcal{F}$ Interferon Res 1986; 6: 543-9.

10 Herberman RB. Interferon and cytotoxic effector cells. In Vilcek J, De Maeyer E, eds. Interferons and the immune system. Amsterdam: Elsevier Science Publishers, 1984: 61-84.

11 Oh SH, Gonisk B, Greenberg SB, Kohl SJ. Enhancement of human neonatal natural killer cytotoxicity to herpes simplex virus with use of recombinant human interferons: Lack of neonatal response to gamma interferon. F Infect Dis 1986; 153: 791-3.

12 De Maeyer E, De Maeyer-Guignard J. Interferon effects on cellular and humoral immunity. In: Baron $S$, Dianzani $F$, Stanton GJ, Fleischmann WR Jr, eds. The interferon system: a current review to 1987. Austin: University of Texas Medical Branch Series in Biomedical Science, 1987: 327-35.

13 Imanishi J, Yokota Y, Kishida T, Mukainaka T, Matsuo A. Phagocytosis-enhancing effect of human leukocyte interferon preparation on human peripheral monocytes in vitro. Acta Virol 1975; 19: 52-5.

14 Rollag H, Degre M. Effect of recombinant interferon- $\gamma$ on protein content, phagocytic, and cytotoxic activity of mouse peritoneal macrophages. $\mathcal{F}$ Interferon Res 1988; 8: mouse peri

15 Dianzani F. Interferon treatments: how to use an endogenous system as a therapeutic agent. $\mathcal{f}$ Interferon Res endogenous system

16 Ameglio F, Capobianchi MR, Dolei A, Tosi R. Differential effects of gamma interferon on expression of HLA Class II molecules controlled by the DR and DC loci. Infect Immun 1983; 42: 122-5.

17 Collins T, Korman AJ, Wake CT, et al. Immune interferon activates multiple class II major histocompatibility complex genes and the associated invariant chain gene in human endothelial cells and dermal fibroblasts. Proc Natl Acad Sci USA 1984; 81: 4917-21.

18 Eddleston ALWF. Overview of HBV pathogenesis. In: Hollinger FB, Lemon SM, Margolis HS, eds. Viral hopatitis and liver disease. Baltimore: Williams \& Wilkins, hepatitis and live

19 Tolentino P, Dianzani F, Zucca M, Giacchino R. Decreased Tolentino P, Dianzani F, Zucca M, Giacchino R. Decreased
interferon response by lymphocytes from children with chronic hepatitis. F Infect Dis 1975; 132: 459-63.

20 Ikeda T, Lever AML, Thomas HC. Evidence for a deficiency of interferon production in patients with chronic hepatitis B virus infection acquired in adult life. Hepatology 1986; 6: 962-5.

21 Pitha PM, Billelo JA, Riggin CH. Effect of interferon on retrovirus replication. Tex Rep Biol Med 1982; 41: 603-9.

22 Friedman R. Effect of interferons on cell membrane. Tex Rep Biol Med 1982; 41: 313-6.

23 Bocci V. Evaluation of routes of administration of interferon in cancer: A review and a proposal. Cancer Drug Deliver in cancer: A review

24 Dianzani F, Baron S. Unexpectedly rapid action of human interferon in physiological conditions. Nature 1975; 257: 682-4

25 Antonelli G, Currenti M, Turriziani O, Dianzani F. Neutralizing antibodies to interferon-alpha: Relative Neutralizing antibodies to interferon-alpha: Relative frequency in patients treated with different

26 Dianzani F, Milella M, Antonelli G, et al. Antibodies to IFN Dianzani $F$, Milella $M$, Antonelli $G$, et al. Antibodies to IFN
and response to therapy in chronic hepatitis $C$ virus infection. $\mathcal{F}$ Interferon Res 1992; 12: S108. 